\title{
CYTOGENETIC ABNORMALITIES AND THERAPY-RELATED MYELODYSPLASTIC SYNDROMES IN RHEUMATIC DISEASE
}

\author{
CONOR J. MCCARTHY, SUSAN SHELDON, CHARLES W. ROSS, and W. JOSEPH MCCUNE
}

Objective. To describe the myelodysplastic syndromes (MDS) and cytogenetic abnormalities that occur in patients who have been treated with alkylating drugs for their rheumatic disease.

Methods. Patients with rheumatic disease who developed MDS after current or previous treatment with alkylating drugs were selected for evaluation by chart review and cytogenetic studies.

Results. Eight patients with rheumatic disease (mean age 56.9 years) developed MDS over the study period. Seven had received oral cyclophosphamide and 1 chlorambucil as their main immunosuppressive drug. The mean total cumulative dose of cyclophosphamide or chlorambucil was $118 \mathrm{gm}$ and $6.5 \mathrm{gm}$, respectively, over a period of 2-10 years. The cytogenetic abnormalities included a deletion of all or part of chromosome 7 in 5 patients, while 4 had a deletion of part of the long arm of chromosome 5. Six of the patients have since died.

Conclusion. Large cumulative doses of cyclophosphamide and chlorambucil were associated with the development of MDS, the occurrence of abnormalities of chromosome 5 and/or chromosome 7 deletions, and a poor prognosis.

The occurrence of myelodysplastic syndromes (MDS) after exposure to alkylating drugs is frequently associated with chromosomal abnormalities, particularly of chromosome 5 and/or chromosome 7 (1-3). These changes are often associated with a poor prognosis (1). Treatment of rheumatic disease with alkylating drugs is associated with the development of MDS and hemato-

Research Fund.

Supported in part by the Herb and Carol Amster Lupus

Conor J. McCarthy, MD, MRCPI, Susan Sheldon, PhD, Charles W. Ross, MD, W. Joseph McCune, MD: University of Michigan Medical Center, Ann Arbor.

Address reprint requests to Conor McCarthy, MD, MRCPI, Department of Rheumatology, Mater Misericordiae Hospital, University College Dublin, Eccles Strect, Dublin 7, Ireland.

Submitted for publication September 12, 1997; accepted in revised form February 11, 1998. logic malignancies (4), and conversely, patients with MDS can develop rheumatic manifestations $(5,6)$. However, to date, no study has described the cytogenetic abnormalities in patients with rheumatic diseases who have developed therapy-related MDS. This study describes the MDS and cytogenetic abnormalities that occurred in a group of patients with rheumatic disease who had been treated with alkylating drugs.

\section{PATIENTS AND METHODS}

All patients with rheumatic disease who attend our clinics and receive immunosuppressive drugs are monitored regularly, with monthly complete blood cell counts, for the development of hematologic abnormalities. All patients with rheumatic disease who had received alkylating drugs and were known to have developed MDS over the previous 7 years were included in this study. Their hospital charts were reviewed for information regarding their rheumatologic diagnosis, as well as the type, cumulative dose, and duration of the alkylating drug. Additional information regarding cytogenetic abnormalities, the type of MDS, and the patient outcome was obtained from chart and pathologic review. In each case, treatment with an alkylating drug was initiated because of serious complications of the disease.

The classification of MDS has been previously described (7). Cytogenetic studies were performed on cells from a bone marrow aspirate obtained during a routine workup for the hematologic disorder. In all cases, the bone marrow and karyotype were reviewed by a pathologist and cytogeneticist, respectively.

\section{RESULTS}

Table 1 characterizes the patients in this study. Five men and 3 women, with a mean age of 56.9 years (range 36-75 years), developed MDS over the 7-year study period. Their clinical presentations were varied. Five presented with cytopenia on routine laboratory testing. Two patients presented with increasing fatigue related to anemia. Seven patients had received cyclophosphamide and 1 chlorambucil as their main immunosuppressive drug. The mean cumulative cyclophospha- 
Table 1. Characteristics of the study patients*

\begin{tabular}{|c|c|c|c|c|c|c|c|}
\hline \multirow[b]{2}{*}{ Patient/age/sex } & \multirow[b]{2}{*}{ Rheumatologic diagnosis } & \multicolumn{3}{|c|}{ Alkylating drug } & \multirow[b]{2}{*}{$\begin{array}{l}\text { Type of } \\
\text { MDS }\end{array}$} & \multirow[b]{2}{*}{$\begin{array}{l}\text { Cytogenetic } \\
\text { abnormality }\end{array}$} & \multirow[b]{2}{*}{ Outcome } \\
\hline & & Type & $\begin{array}{l}\text { Cumulative } \\
\text { dose, gm }\end{array}$ & $\begin{array}{l}\text { Duration, } \\
\text { years }\end{array}$ & & & \\
\hline $1 / 64 / \mathrm{M}$ & Wegener's granulomatosis & $\mathrm{CYC}$ & 135 & 6 & RAEB-T & $7 q-$ & Died \\
\hline $2 / 36 / \mathrm{F}$ & $\begin{array}{l}\text { Takayasu arteritis/Cogan's } \\
\text { syndrome }\end{array}$ & CYC & 91.2 & 2 & MDS-NOS & $7 q^{-}$ & Living \\
\hline $3 / 64 / \mathrm{M}$ & $\begin{array}{l}\text { Rheumatoid arthritis/ } \\
\text { Sjögren's syndrome }\end{array}$ & $\mathrm{CYC}$ & 112.5 & 3 & RAEB & $5 q-, 7 q-$ & Died \\
\hline $4 / 75 / \mathrm{F}$ & Wegener's granulomatosis & CYC & 120 & 2 & RAEB-T & $\begin{array}{c}\text { Monosomy } \\
7\end{array}$ & Living \\
\hline $5 / 46 / \mathrm{M}$ & Goodpasture's syndrome & CYC & 110 & 3 & MDS-NOS & $\begin{array}{c}\text { Monosomy } \\
7\end{array}$ & Died \\
\hline $6 / 45 / \mathrm{M}$ & Cerebral angiitis & $\mathrm{CYC}$ & 140 & 4 & MDS-NOS & $5 q-$ & Died \\
\hline $7 / 72 / \mathrm{F}$ & Polymyositis & CHL & 6.5 & 3 & RAEB & $5 q-$ & Died \\
\hline 8/57/M & Wegener's granulomatosis & CYC & 109 & 2 & MDS-NOS & $5 q-$ & Died \\
\hline
\end{tabular}

* Myelodysplastic syndromes (MDS) are defined in ref. $7 . \mathrm{CYC}=$ cyclophosphamide; RAEB-T $=$ refractory anemia with excess blasts in transformation; MDS-NOS = MDS not otherwise subclassified; $\mathrm{CHL}=$ chlorambucil.

mide dose was $118 \mathrm{gm}$ (SD $16.6 \mathrm{gm}$ ), with a mean treatment period of 4.4 years (range $2-10$ years). The chlorambucil-treated patient received a total dose of 6.5 gm. Of the cyclophosphamide-treated patients, 3 had also received 2 other immunosuppressive drugs (methotrexate and azathioprine in 1 , methotrexate and cyclosporin $A$ in 1, and chlorambucil [total dose $3.6 \mathrm{gm}$ ] and methotrexate in 1) and 1 had received a different immunosuppressive drug (chlorambucil at a total dose $1.4 \mathrm{gm})$.

The mean time from the start of treatment to the development of MDS was 8.25 years (range 2-19 years). The mean time from the diagnosis of the rheumatic disease to the development of MDS was 10.6 years (range 7-19 years). The mean time from discontinuation

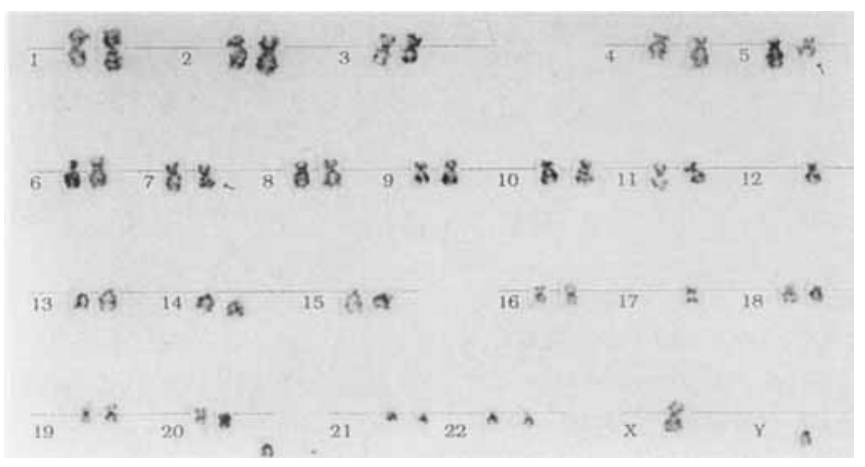

Figure 1. Karyotype from a patient with rheumatoid arthritis and vasculitis, showing deletions of part of the long arm of chromosomes 5 and 7 (arrows) as well as 2 chromosomes that could not be identified (markers; bottom left) and monosomies 12 and 17. These abnormalities were present in all cells analyzed. of the alkylating drug to development of MDS was 2.4 years (range $0-4$ years).

Figure 1 shows the karyotype of a patient with rheumatoid vasculitis, which necessitated treatment with cyclophosphamide. A total cumulative dose of $112.5 \mathrm{gm}$ of cyclophosphamide was administered over 3 years. $\mathrm{He}$ developed refractory anemia with excess blasts 5 years after starting cyclophosphamide. The karyotype shows deletions of part of the long arms of chromosomes 5 and 7. He died 8 months after his MDS was diagnosed. In Figure 2, a second karyotype is shown, with a deletion of part of the long arm of chromosome $5(5 q-)$. This patient had Wegener's granulomatosis and had received a total cumulative dose of $109 \mathrm{gm}$ of cyclophosphamide. He died from complications of the MDS 19 years after his rheumatologic diagnosis.

Cytogenetic abnormalities in chromosome 7 oc-

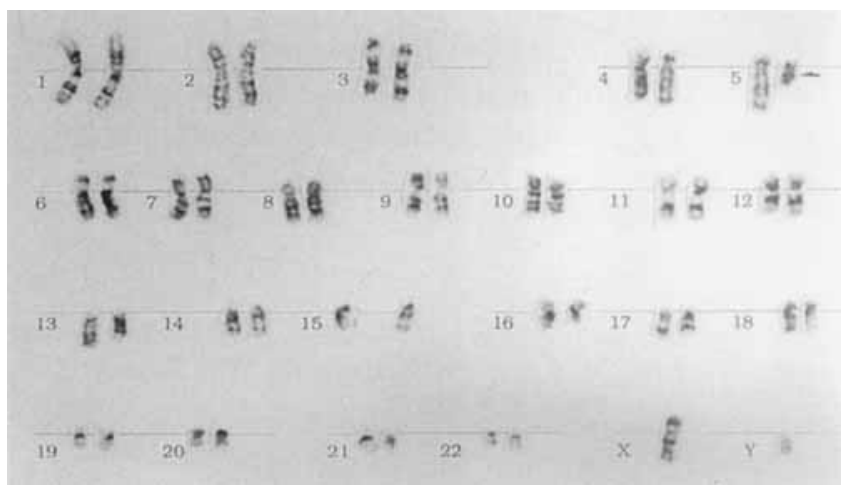

Figure 2. Karyotype from a patient with Wegener's granulomatosis, showing a deletion in part of the long arm of chromosome 5 (arrow). 
curred in 5 patients, while abnormalities in chromosome 5 occurred in 4 patients (the patient described above had abnormalities in both chromosome 5 and chromosome 7). The cytogenetic changes described in these patients are characteristic of therapy-related MDS. In contrast, the histologic features were frequently minimal. The outcome was poor, with 6 of 8 patients dying from complications of their MDS. Four of these had changes in chromosome 5.

\section{DISCUSSION}

Up to $80 \%$ of individuals with therapy-related MDS or therapy-related acute myeloid leukemia have loss of chromosomal material from chromosome 5 and/or chromosome $7(2,8)$. In this study, we report the types of MDS and cytogenetic abnormalities that occurred in a group of hospital-based patients with rheumatic diseases after treatment with alkylating drugs. While these patients had different indications for treatment with alkylating drugs, they all had received large doses of alkylating agents. Their outcome was poor, particularly in those patients with abnormalities of chromosome 5 , in a relatively young population of patients. This is consistent with another report of a poor prognosis in cancer patients who developed MDS after treatment with alkylating drugs (1). Patients with MDS can develop rheumatic disease manifestations $(5,6)$, with a third of patients developing chromosomal abnormalities (5). To date, as far as we are aware, there have been no reports of cytogenetic abnormalities in chromosome 5 in patients with rheumatic disease. This suggests that the changes documented herein are likely to be a secondary phenomenon related to high cumulative doses of the alkylating drugs $(4,8)$.

We can only speculate as to the duration of risk of MDS following discontinuation of the alkylating drug. In this study, our patients developed MDS up to 4 years after cessation of the alkylating drug, but in patients treated for cancer, there have been reports of MDS developing up to 12 years after treatment $(2,8-10)$. In contrast, one study suggested that there is no increased risk of therapy-related MDS 10 years after discontinuation of treatment (11). The actual risk of developing MDS in our population of patients treated with alkylating drugs is not known; however, followup of our patients is ongoing. We are currently following up 24 patients on a regimen of oral cyclophosphamide and over 100 patients who have received intravenous cyclophosphamide. We are also following up 5 patients being treated with chlorambucil.
Many of these patients have also been treated with methotrexate and/or azathioprine. Azathioprine may increase the risk of some malignancies. However, in rheumatic disease, neither of these compounds has been clearly implicated in the development of MDS $(12,13)$. We can only suggest that patients who have been treated with alkylating drugs and methotrexate or azathioprine should be followed up very closely.

A deletion of the long arm of chromosome 5 $(5 q-)$ in patients with refractory anemia was described in 1974 , and is now called the $5 q-$ syndrome $(8,14,15)$. The chromosome breakpoints vary. However, there is a region of overlap that is consistently lost (16). This region on $5 \mathrm{q}$ contains the genetic information for a large number of growth factors and growth factor receptor genes, which play an important role in normal myeloid growth and differentiation. In addition, the loss of heterozygosity at some loci, leading to oncogene expression, may be important in the development of MDS (16).

The findings of this study suggest that high cumulative doses of alkylating drugs present a risk for the development of MDS, with associated cytogenetic abnormalities of chromosomes 5 and/or 7 in patients with rheumatic diseases. Long-term hematologic monitoring of patients who have received cumulative doses of $>100 \mathrm{gm}$ of cyclophosphamide is strongly recommended. The occurrence of hematologic abnormalities in patients with rheumatic disease who have received high cumulative doses of alkylating drugs may herald the onset of MDS. Bone marrow evaluation should include cytogenetic studies because these may have diagnostic and prognostic implications.

\section{REFERENCES}

1. Bloomfield CD. Chromosome abnormalities in secondary myelodysplastic syndromes. Scand J Haematol 1997;45 Suppl:82-90.

2. Rowley JD, Golomb HM, Vardimam JW. Nonrandom chromosome abnormalities in acute leukemia and dysmyelopoietic syndromes in patients with previously treated malignant disease. Blood 1981;58:759-67.

3. Anderson RL, Bagby GCJ, Magenis RE, Koler RD. Therapyrelated preleukemic syndrome. Cancer 1980;47:1867-71.

4. Richert-Boe KE. Hematologic complications of rheumatic disease. Hematol Oncol Clin North Am 1987;1:307-20.

5. Castro M, Conn DL, Su DWP, Garton JP. Rheumatic manifestations in myelodysplastic syndromes. J Rheumatol 1997;18:721-7.

6. Kuzmich PD, Ecker GA, Karsh J. Rheumatic manifestations in patients with myelodysplastic syndromes. J Rheumatol 1994;21: $1649-54$.

7. Bennett JM, Catovsky D, Daniel MT, Flandrin G, Gatlin DAG, Granlick HR. Proposals for the classification of the myelodysplastic syndromes. Br J Haematol 1982;51:189-99.

8. LeBeau MM. Deletions of chromosome 5 in malignant myeloid disorders. Canecr Surv 1992;15:143-59.

9. Kantarjian HM, Estey EH, Keating MJ. Treatment of therapy- 
related leukemia and myelodysplastic syndrome. Hematol Oncol Clin North Am 1993;7:81-107.

10. Kantarjian HM, Keating MJ. Therapy-related leukemia and myelodysplastic syndrome. Semin Oncol 1987;14:435-43.

11. Blayney DW, Longo DL, Young RC, Greene MH, Hubbard SM, Postal MG, et al. Decreasing risk of leukemia with prolonged follow-up after chemotherapy and radiotherapy for Hodgkin's disease. N Engl J Med 1987;316:710-4.

12. Lynch JP, McCune WJ. Immunosuppressive and cytotoxic pharmacotherapy for pulmonary disorders. Am J Respir Crit Care Med $1997 ; 155: 395-420$.

13. Moder KG, Tefferi A, Cohen MD, Menke DM, Luthra HS
Hematologic malignancies and the use of methotrexate in rheumatoid arthritis: a retrospective study. Am J Med 1995;99: 276-81.

14. Van den Berghe $H$, Vermaelen $K$, Mecucci $C$, Barbieri D, Tricot G. The 5q- anomaly. Cancer Genet Cytogenet 1985;74:8-12.

15. Nagarajan L, Zhao L, Lu X, Warrington JA, Washmuth JJ, Siciliano $\mathbf{M}$, et al. 5q-chromosome. Cancer Genet Cytogenet 1994;74:8-12.

16. Boultwood J, Rack K, Kelly S, Madden J, Sakaguchi AY, Wang L-M, et al. Loss of both CSF1R (FMS) alleles in patients with myelodysplasia and chromosome 5 deletion. Proc Natl Acad Sci U S A 1991;88:6176-80. 